\title{
Numerical and experimental analysis on tensile properties of banana and glass fibers reinforced epoxy composites
}

\author{
A SHADRACH JEYASEKARAN ${ }^{1,2}$, K PALANI KUMAR ${ }^{3, * \mathbb{D}}$ and S RAJARAJAN ${ }^{4}$ \\ ${ }^{1}$ Anna University, Chennai 600025 , India \\ ${ }^{2}$ Department of Mechanical Engineering, St. Peter's College of Engineering and Technology, Chennai 600054, \\ India \\ ${ }^{3}$ Department of Mechanical Engineering, Sri Sai Ram Institute of Technology, Chennai 600044, India \\ ${ }^{4}$ Department of Electronics and Communication Engineering, Sri Sai Ram Institute of Technology, \\ Chennai 600044, India \\ e-mail: shadji2000@yahoo.co.in; palanikumar_k@yahoo.com; srajayaganesh@gmail.com
}

MS received 23 June 2015; revised 4 March 2016; accepted 23 May 2016

\begin{abstract}
In present day scenario, moving towards an environment friendly material is a key issue for manufacturing industries in order to provide suitable alternatives for the existing conventional materials. Natural fibers have higher economic impact and miniature in density when compared to glass fibers while making composites. Though the strength of natural fibers is not as high as glass fibers, their specific properties are comparable. In this paper a study has been carried out to find the tensile characteristics of hybrid composite made by intruding unidirectional banana and glass fibers into epoxy resin mixture. The hand lay-up method of fabrication was employed in preparing the composites of unidirectional glass fiber (UGF) and unidirectional banana/glass fiber (U B/G F). Tensile properties of the composites are verified using ANSYS. It is observed from the findings that the numerical analysis is found to be higher than experimental analysis. Hybridization of banana fiber shows better tensile properties. It is evident from the result that, comparatively equal displacement is obtained for the varying load for both the composites. The surface morphology of the tested composites is analyzed through scanning electron microscope (SEM).
\end{abstract}

Keywords. Banana fiber; glass fiber; unidirectional; tensile; ANSYS; SEM.

\section{Introduction}

Green environment for future motivated researchers to seek for an eco-friendly alternative. The interest in exploring the other available materials from agro industries has grown in recent years. The manufacturing and utilization of improved natural composites has not yet begun on a large commercial scale. Ayensu [1] stated that the natural fibers are easily available and are abundant in nature from which preparation of composite materials is not a complicated task utilizing a nominal amount of input energy. Furthermore as they are having low density; composites with greater specific strength can be manufactured provided the natural fibers are non-hazardous and eco-friendly. Palanikumar et al [2] reviewed the mechanical properties of natural fibers, their extraction process with suitable manufacturing process employed along with the resins used in the composite. Sharma et al [3] studied the fibers obtained from rice husk, jute, banana, and coconut and have concluded that they possess excellent physical and mechanical

*For correspondence properties among which the mechanical properties of banana fiber reinforced composite is optimally good. Udaya Kiran et al [4] studied the tensile properties of the composites made from short sun hemp, banana, and sisal and it has been identified that sun hemp shows favorable tensile strength. Indira et al [5] used resin transfer molding (RTM) and compression molding (CM) methods to make banana fiber phenol formaldehyde resin composites. Its tensile properties are determined as a function of fiber length and fiber loading. The fiber loading values are found to be higher for RTM while compared with CM composites while measuring their tensile properties. Scanning electron microscope image indicated that the extent of fiber pullout was lower for RTM composites. From this study fabrication methodology also plays a vital role in increasing the mechanical properties of composites. Venkateshwaran et al [6] analyzed hybrid composites of sisal/banana for its tensile properties which was determined by rule of hybrid mixture. Its values are found to be higher while compared with experimental values. Variations of tensile properties are also observed due to the occurrence of microvoids in the composites during the fabrication. Rathika et al [7] 
determined the mechanical characteristics of sisal-PALFbanana-glass fiber reinforced with polyester hybrid composites indicated that there is a vast increase in the superior properties like tensile, flexural and impact strength of sisalPALF-banana fiber when it is reinforced with glass fiber in the polyester composites. Ramesh et al [8] have carried out experiment on the tensile and flexural properties of hybrid glass fiber-sisal/jute reinforced epoxy composite to analyze the interfacial characteristics of materials, fractured surfaces of the internal structure and material failure morphology. From the observation the addition of sisal fiber with glass fiber reinforced composite shows greater tensile properties while compared with the jute fiber reinforced with glass fiber reinforced composites. Maleque et al [9] observed the increment of tensile strength up to $90 \%$ is noted on the composite made from pseudo-stem banana woven fabric reinforced into epoxy while compared with virgin epoxy composite. Arumuga Prabu et al [10] identified the mechanical properties such as tensile, flexural and impact are found to be improved marginally by adding red mud (an industrial waste) into sisal and banana fiber reinforced unsaturated polyester composite fabricated by compression molding technique. Thiruchitrambalam et al [11] experimented by treating sodium lauryl sulfate as an alternative to sodium hydroxide in woven Banana/Kenaf hybrid composite. It is observed that tensile, flexural and impact strength is found to be increased. Sathishkumar et al [12] studied the tensile properties of the newly identified snake grass fiber composite with isophthallic polyester resin. From the experimental evidence the volume fraction increases the tensile and flexural strength of the composite. Satnam Singh et al [13] experimented by varying the percentage of fiber with respect to weight which shows difference in tensile and flexural strength of glass fiber reinforced epoxy composites compared with unreinforced epoxy. Tensile strength is observed to be increased by $14.5 \%$ and flexural is about to $123.65 \%$ when $20 \%$ of fiber weight is added over pure epoxy. Because of high flexural strength, stiffness of the composite is improved drastically. Maximum stresses are observed for tensile and flexural at the middle of the specimen where the fracture is originated, and it is proved by the results of finite element analysis. Subba Rao et al [14] adopted the molecular mechanics based finite element analysis to evaluate the mechanical properties of zigzag, armchair and chiral single wall carbon nanotubes of different diameters and chiralities. The finite element model of the CNT was constructed, appropriate boundary conditions were applied and the behavior of mechanical properties of CNT was studied. The calculated values of the mechanical properties are agreed well with the published literature data. Gutu [15] made tensile analyses for E glass woven roving and chopped strand mat composites. Finite element results naturally involve some deviations from exact solutions due to characteristics of composites. Matrix crack, fiber failures and increasing stiffness are considered in deformation mechanics of real testing process, and it is not considered in theoretical approach. Lakshmi Narayana et al [16] had carried out a numerical study using finite element method, to examine the effects of square and rectangular cutout on the buckling behavior of graphite/epoxy symmetrically laminated rectangular composite plate subjected to various linearly varying in-plane compressive loads. It is observed that the various linearly varying in-plane loads and boundary conditions have a substantial influence on buckling strength of rectangular composite plate with square/rectangular cutout. Md. Rashnal Hossain et al [17] made jute composites with the vacuum assisted resin infiltration techniques with different orientations. For all developed composites, experimental results revealed that the tensile properties of the developed composites are strongly dependent on the tensile strength of jute fiber, while comparing with the theoretical values. Mohammed Khalifa et al [18] carried out experiments for tensile tests of banana fiber reinforced epoxy composite with difference in fiber diameters. It is observed that the tensile strength increases when the diameter of fibers (volume fraction) increases. Finite element analysis using ANSYS software has showed that the differences of results obtained from these samples are not significant compared to experimental results. Ihueze et al [19] designed and analyzed plantain fiber reinforced polyester composites of multiaxial stresses in relation to yield limit stresses loaded off the fibers axis. While the rule of mixtures was used in the evaluation of properties of composites in the fiber direction, the evaluation of properties perpendicular or transverse to the fiber direction was done based on the value of the orthogonal stresses evaluated using ANSYS finite element software. From the observations, plantain fiber reinforced polyester composite physical and mechanical properties relevant to the design of components of structures are comparable to the conventional glass fiber reinforced composites. Leandro José da Silva et al [20] identified that apart from the interface transition zone but also the heterogeneity of natural fibers affects the mechanical behavior of unidirectional sisal and banana fiber epoxy composites. The 2D simulation using the elastic properties predicted by the rule of mixture was able to describe the biocomposites behavior, revealing a strong interface condition. The finite element analysis joined with the micromechanical analysis was able to characterize the interface condition of the composite phases, when there is regularity and symmetry of fiber arrangements. Dyson Bruno et al [21] analyzed the hemp fiber reinforced polypropylene and kenaf fiber reinforced epoxy composites using FEA with various fiber volume fractions. The tensile behavior for various ply orientations illustrates that the stress decreases gradually at one point it reaches to critical level. From the result, it is clear that the laminated plate of kenaf fiber reinforced epoxy composites withstand good tensile property at $60 \%$ fiber volume fraction. Velmurugan et al [22] carried out the analysis of tensile properties of palmyra fiber reinforced epoxy composite. The simulation 
was carried out using FEA under different fiber volume fraction and fiber length and validated with the experimental result and found to have less error percentage. Ramakrishnan et al [23] investigated the mechanical properties of vinyl ester resin reinforced with different weight fractions of 17 selected natural fibers by mathematical modeling and ANSYS simulation. From the observations, it is evident that increase in fiber content significantly improves the mechanical properties. The theoretical and ANSYS results indicate that vinyl ester reinforced with the fibers abaca, hemp and banana shows better tensile strength properties. The highest tensile modulus values are obtained for the fibers ramie, abaca, and sisal incorporated in vinyl ester. Similarly, for toughness and impact strength applications, the fibers banana, sisal and cotton are found to be suitable reinforcement for vinyl ester resin. Venkateshwaran et al [24] suggested in construction, automobile and manufacturing industries, composites with natural fibers are highly expected because of its high tensile strength and modulus, as well as for its low density and low elongation. The proper research right now will focus and attract various sectors to move towards these natural fiber composites. In this research experimental and numerical analysis is carried out on the tensile property of unidirectional banana fiber and glass fiber epoxy composite along with scanning electron microscopy (SEM) analysis in order to develop an alternative for conventional materials and initiation to go for commercialization.

\section{Materials and method}

\subsection{Fiber and matrix material}

Unidirectional glass and banana fibers which are presented in figure 1 were procured from Sun tech fiber private limited, and from Anakaputhur Jute weaver association, Chennai. Matrix material selected is epoxy resin LY556 and hardener HY951 as binder for the resin. Composite preparation is carried out at Creative Composites, Chennai.
Tensile testing was carried out at Microlab, NABL Accredited Metallurgical Test Laboratory, Chennai.

\subsection{Preparation of the composite}

The composite is prepared by using epoxy resin LY556 and the hardener HY951 is stirred with a ratio of 10:1. This solution is used as a matrix. The catalyst was added to the epoxy and the mixture was stirred properly with correct timing before applying into the mold. The molds should be dust free before applying epoxy. The unidirectional fibers of banana and glass were used as reinforcements. The types of composites prepared are unidirectional glass fiber epoxy laminate (UGF), and unidirectional banana/glass fiber epoxy laminate (U B/G F). The fabrications of these two laminates were done by adapting the hand lay-up technique. The main advantage of hand lay-up process is its fabrication ease of large and complex parts in a very short time. Furthermore the hand lay-up method uses simple fixtures and tools which are comparatively cheaper than other manufacturing techniques. Each laminate consists of six layers sequentially distributed by the matrix. The dimension of the mold was $300 \mathrm{~mm} \times 300 \mathrm{~mm} \times 4 \mathrm{~mm}$. Plastic film was coated using the silicone spray and the mold was covered with the metal frame for easy removal and to get high surface finish in the laminates. The resin gets distributed uniformly on the entire area of each surface by brushing and pressing with roller, air voids formed are removed completely. Laminates were taken from the mold and curing time is maintained at room temperature for $24 \mathrm{~h}$. After curing process the laminates are hard and dry enough for the cutting process. After the laminates have been set, the burs on the rough edges were cut by using saw cutter and emery sheets were used to remove the rough edges. Thus unidirectional glass fiber epoxy laminate (UGF) is prepared by keeping unidirectional glass fiber mat alternatively in between epoxy resin coatings. In similar way by keeping alternate layers of banana fiber and glass fiber separated by epoxy mixture the second laminate,
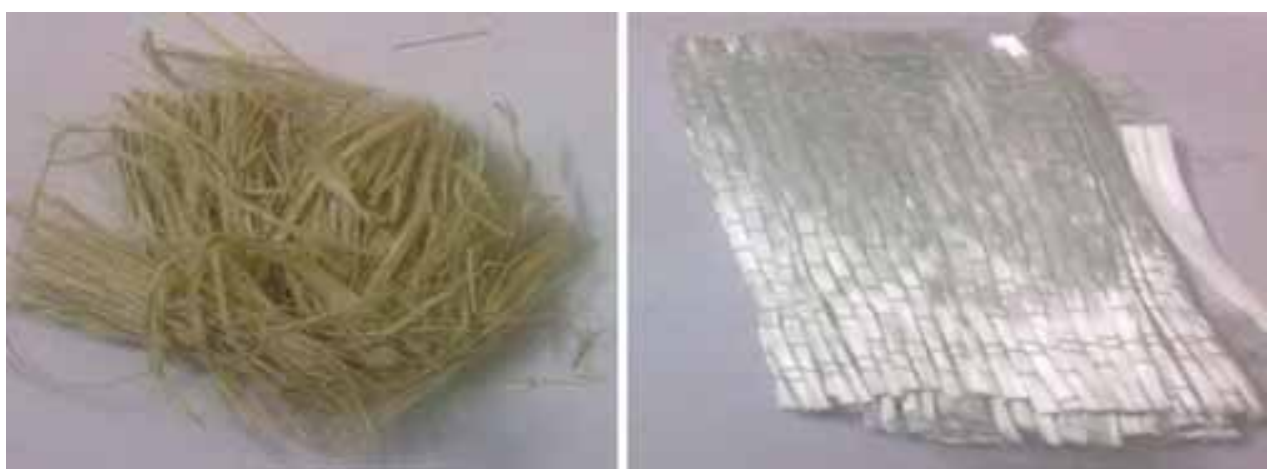

Figure 1. Banana and glass fibers. 
unidirectional banana/glass fiber epoxy laminate (U B/G F) is prepared.

\subsection{Testing of composite material}

Specimens for tensile test were prepared according to the ASTM 3039 standard to measure the tensile properties. The tensile test specimens of both the laminates UGF and $U$ $\mathrm{B} / \mathrm{G} \mathrm{F}$ are shown in figures 2 and 3 . Before commencing the tensile test, the initial length, width and height of specimens are measured. Fix the specimen at top and bottom jaws of universal testing machine to ensure that the fracture will happen at the center of the specimen. The movement of the jaw offers tensile force on the specimen. The samples were tested at a speed of $5 \mathrm{~mm} / \mathrm{min}$ in the universal testing machine. Entire testing process is carried out at room temperature. Specimens prepared as per ASTM 3039 standards from the two different types of laminates UGF and $U$ B/G F were subjected to tensile test for three samples per laminate. The average tensile strength has been taken for both the samples. The sample curves for stressstrain generated automatically from the universal testing machine for tensile test, and its corresponding load-displacement are presented in figures 4-7 during the testing process. The physical properties of glass and banana fiber are represented in table 1 . The tensile test values for various specimens of the UGF and U B/G F epoxy composite are shown in table 2 . The comparative charts for ultimate

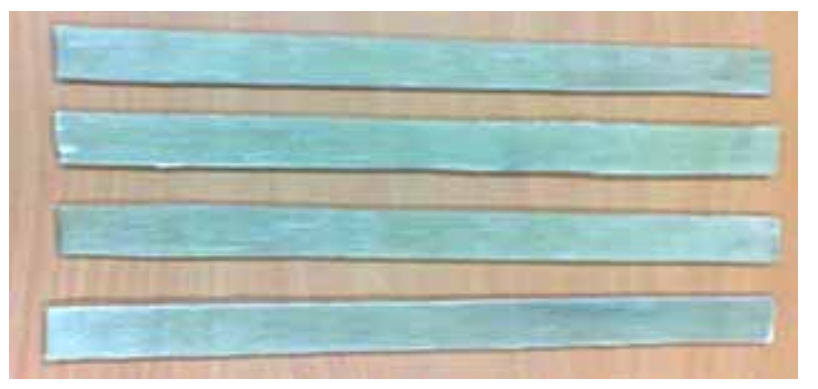

Figure 2. Unidirectional glass fiber specimens (UGF).

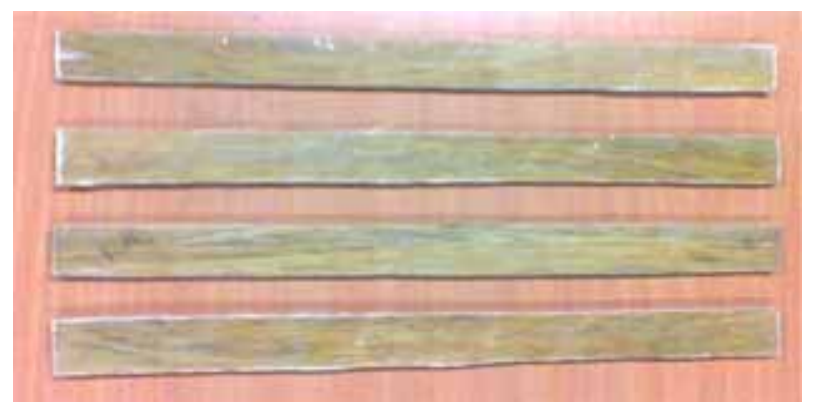

Figure 3. Unidirectional banana/glass fiber specimens ( $\mathrm{U} B / \mathrm{G}$ F). tensile strength and ultimate tensile load of unidirectional glass fiber epoxy composite and unidirectional banana/glass fiber epoxy composite samples are presented in figures 8 and 9 .

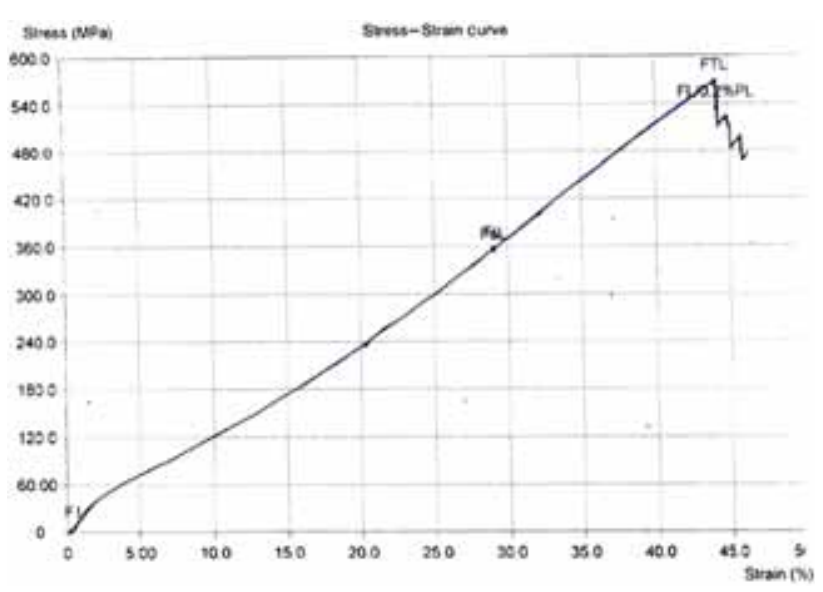

Figure 4. Stress-Strain curve for UGF composite.

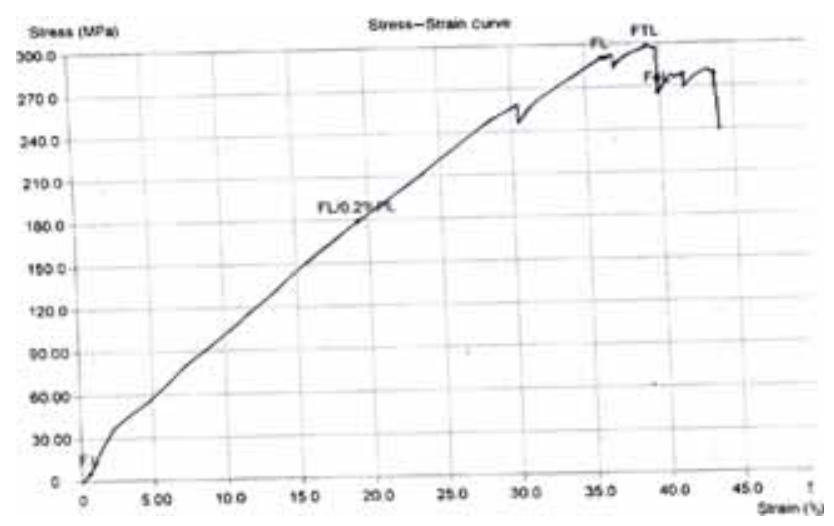

Figure 5. Stress-Strain curve for U B/G F composite.

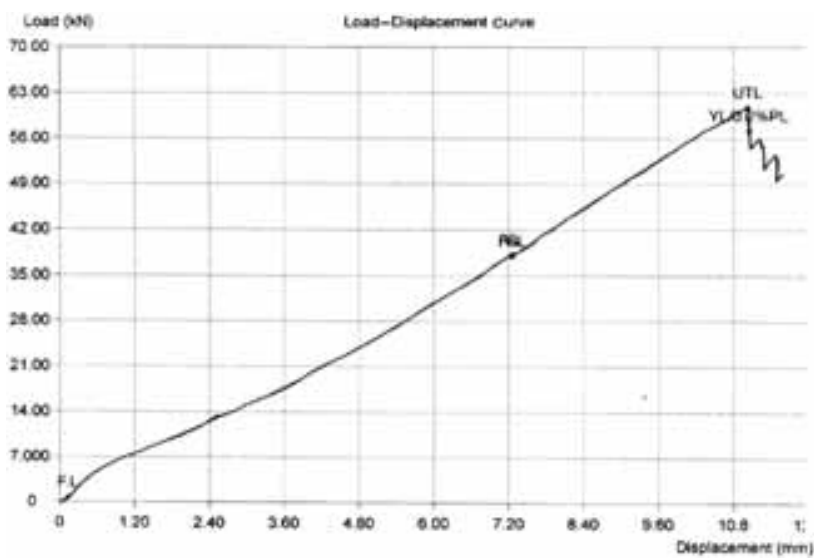

Figure 6. Load-Displacement curve for UGF composite. 


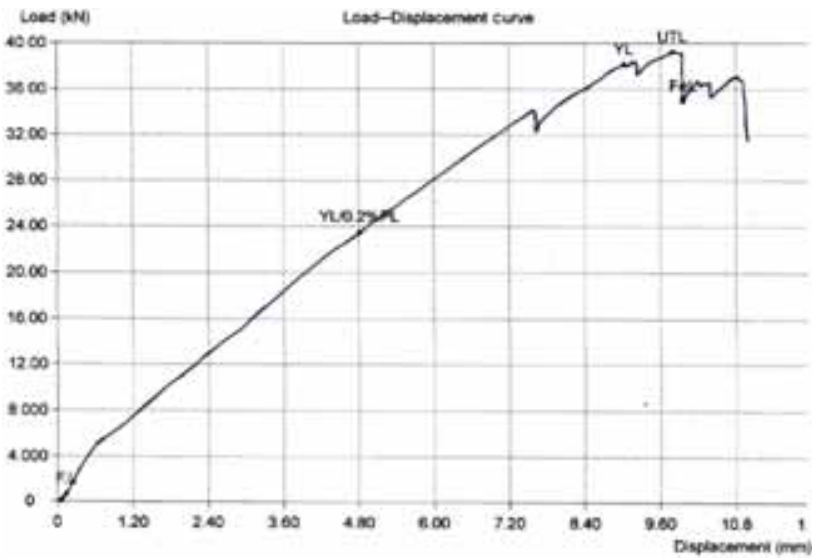

Figure 7. Load-Displacement curve for U B/G F composite.

Table 1. Properties of banana and glass fiber.

\begin{tabular}{lcc}
\hline Properties & Banana & Glass \\
\hline Density $\left(\mathrm{g} / \mathrm{cm}^{3}\right)$ & 1.35 & 2.54 \\
Diameter $(\mu \mathrm{m})$ & $120 \pm 5.8$ & $5-25$ \\
Tensile strength $(\mathrm{MPa})$ & $550 \pm 6.7$ & $2000-3500$ \\
Young's modulus $(\mathrm{GPa})$ & 20 & 70 \\
Elongation at break $(\%)$ & $5-6$ & 2.5 \\
\hline
\end{tabular}

\section{Tensile test result for ANSYS}

ANSYS is one of the efficient tools available for design analysis. The finite element system is one among the general solution for doing highly complicated analysis. For many engineering problems analytical solutions are not suitable because of the complexity of the material properties, the boundary conditions and the structure itself. Subdivisions are assembled to represent a body or structure known as finite elements. The finite element method translates partial differential equation problems into a set of linear algebraic equations shown in Eq. (1).

$$
[K]\{q\}=\{F\}
$$

$K=$ Stiffness matrix, $q=$ Nodal displacement vector, $F=$ Nodal vector force.

Table 2. Tensile test for the composite materials.

\begin{tabular}{lcccccccc}
\hline & \multicolumn{3}{c}{ Unidirectional glass fiber $(\mathrm{UGF})$} & & \multicolumn{3}{c}{ Unidirectional banana/glass fiber (UB/GF) } \\
\cline { 2 - 3 } Observation/specimen & $\mathrm{T} 1$ & $\mathrm{~T} 2$ & $\mathrm{~T} 3$ & & $\mathrm{~T} 1$ & $\mathrm{~T} 2$ & $\mathrm{~T} 3$ \\
\hline Ultimate tensile load $(\mathrm{kN})$ & 60.75 & 52.65 & 60.25 & & 38.4 & 39.23 & 39 \\
Ultimate tensile strength (Mpa) & 567.7 & 463.59 & 465.4 & & 295.39 & 298.29 & 296.39 \\
Displacement $(\mathrm{mm})$ & 11 & 10.6 & 10.8 & & 12.2 & 10 & 11 \\
\hline
\end{tabular}

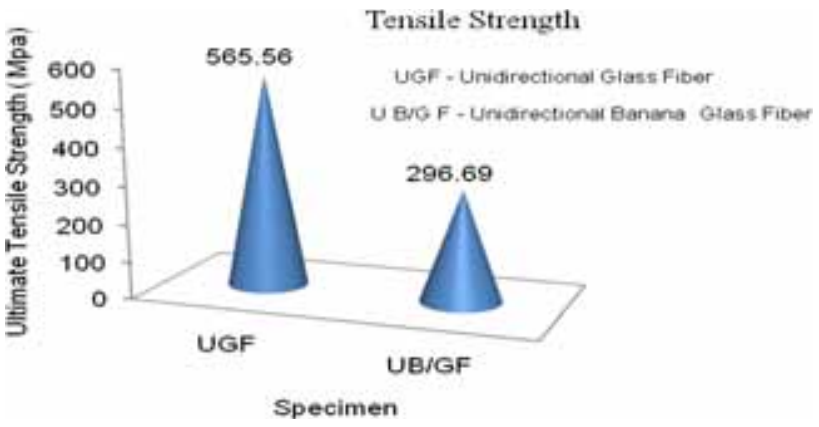

Figure 8. Tensile strength comparison chart.

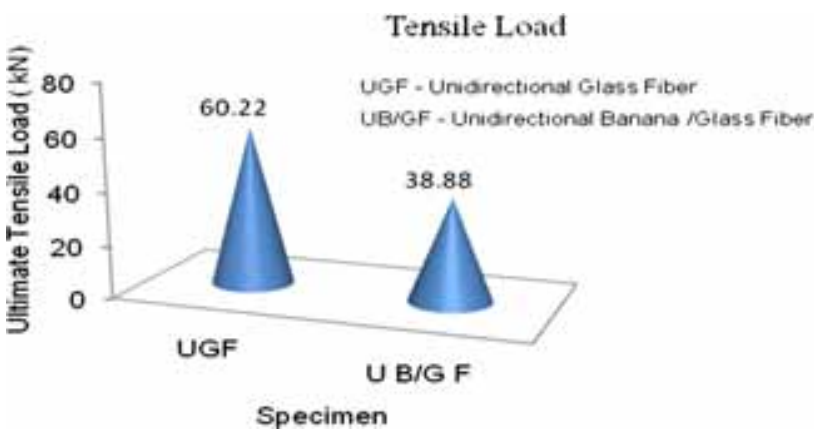

Figure 9. Tensile load comparison chart.

Modeling with ANSYS is carried out by Geometry and Element type procedure which is presented in figure 12. For performing this analysis the material property, Young's modulus, Poisson's ratio, density, boundary conditions and load conditions were applied similar to the experimental condition. Shell elements are typically used for structure where the thickness is negligible compared to its length and width. Nevertheless, a plate modeled with solid element would provide similar results. The disadvantage lies in the computation time. ANSYS provides large choices of elements [25]. The element type used was solid 4-node 181 shown in figure 13. Thin to thick shell structures are analyzed suitably by SHELL181. Each node has six degrees of freedom and it is a four-node element: translations in the $x, y$, and $z$ directions, and rotations about the $x, y$, and $z$-axes. For generating mesh, triangular option has to be used as filler elements. Applications such as linear, nonlinear and rotational are well-suited. In nonlinear analysis, change in shell 


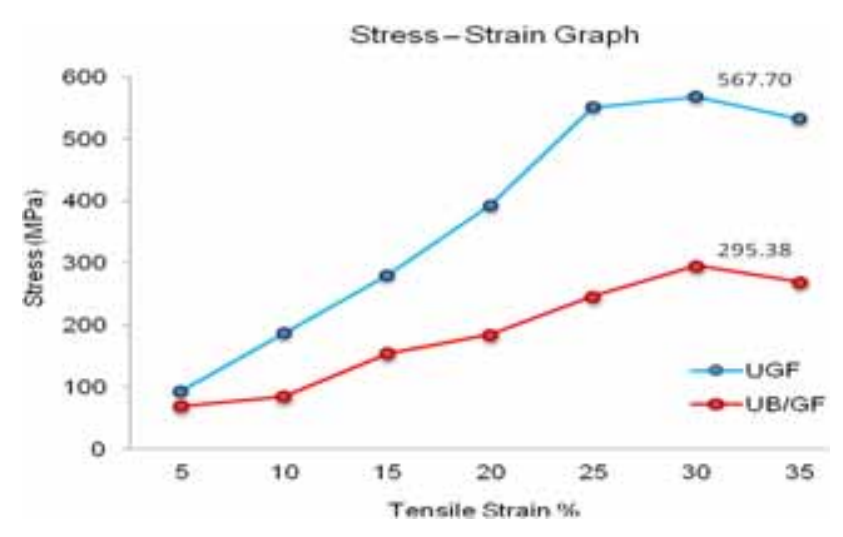

Figure 10. Tensile stress-strain comparison graph.

thickness is accounted. Both full and reduced integration schemes are supported in the element domain. Modeling composite shells or sandwich construction is done by layered applications. The first-order shear-deformation theory governs the accuracy in modeling composite shells. Based on logarithmic strain and true stress measures, the element formulation is carried out. The default orientation for this element has the S1 (shell surface coordinate) shown in Eqs. (2) and (3) and its axis is matched with the first parametric direction of the element at the mid of the element, which connects the center of edges LI and JK and it is represented in figure 13 . In every case, the axis can be defined as

$$
\begin{aligned}
& S_{1}=\frac{\partial\{X\}}{\partial s} /\left(\left|\frac{\partial\{X\}}{\partial s}\right|\right) \\
& \{X\}=\sum_{i=1}^{8} h^{i}(s, r)\{X\}^{i}
\end{aligned}
$$

$\{x\}^{\mathrm{I}},\{x\}^{\mathrm{J}},\{x\}^{\mathrm{K}},\{x\}^{\mathrm{L}}=$ global nodal coordinates.

SHELL181 includes the linear effects of transverse shear deformation. The transverse shear stiffness of the element is a $2 \times 2$ matrix as shown below in Eq. (4),

$$
E=\left(\begin{array}{ll}
E_{11} & E_{12} \\
s y m & E_{22}
\end{array}\right)
$$

With isotropic material for a single-layer shell, default transverse shear stiffness is shown in Eq. (5),

$$
E=\left(\begin{array}{cc}
k G h & 0 \\
0 & k G h
\end{array}\right)
$$

In the above matrix, $k=5 / 6, G=$ shear modulus, and $h=$ thickness of the shell.

The isotropic elastic modulus $=\mathrm{EX}$ and Poisson's ratio $=$ NUXY is a default parameter in ANSYS. Compressibility of the material is specified by Poisson's ratio. If greater than or equal to 0.5 , Poisson's ratio is set to 0.5 (fully incompressible), if less than 0 , Poisson's ratio is set

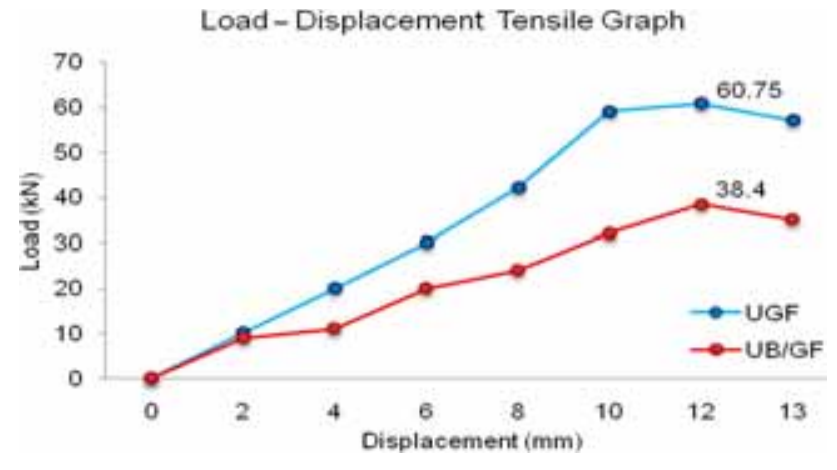

Figure 11. Tensile load-displacement comparison graph.

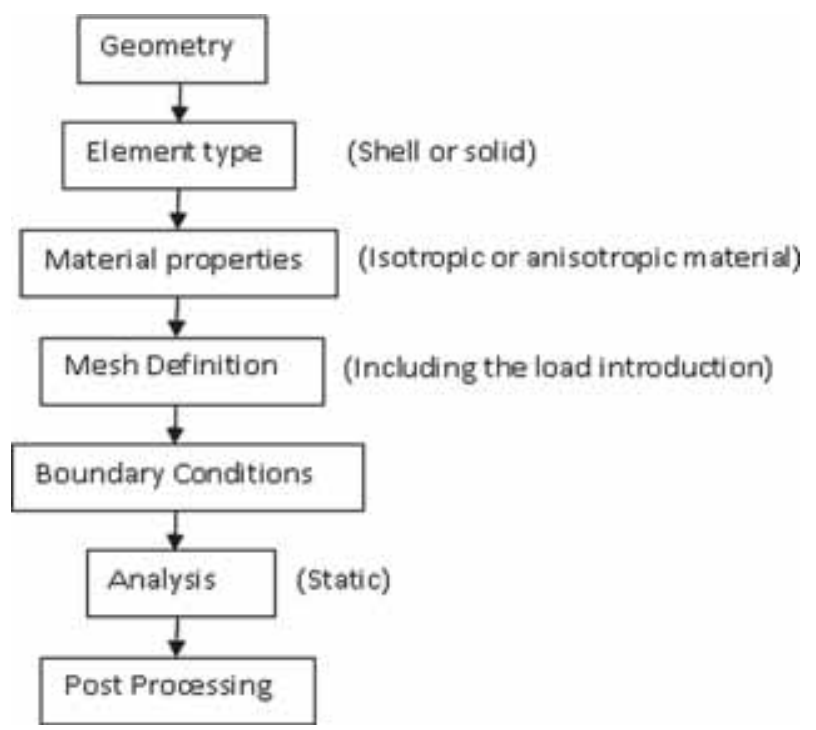

Figure 12. Geometry and element type procedure.

to 0 . The displacement and force were plotted using ANSYS are presented in figures 14-17. The comparison was made with experiment results. ANSYS results were compared with the experimental results of all the specimens for tensile test and it is represented in figures 18 and 19 .

\section{Results and discussions}

\subsection{Tensile properties}

This study is used to investigate the tensile property of unidirectional glass fiber reinforced epoxy composite and unidirectional banana/glass fiber reinforced epoxy composite; the tested values are evaluated and compared. The composite samples of UGF and $\mathrm{U} B / \mathrm{G} \mathrm{F}$ are tested in universal testing machine. The readings taken for the tensile test of the two different composite samples are given in table 2 . The average ultimate tensile load is found to be as 


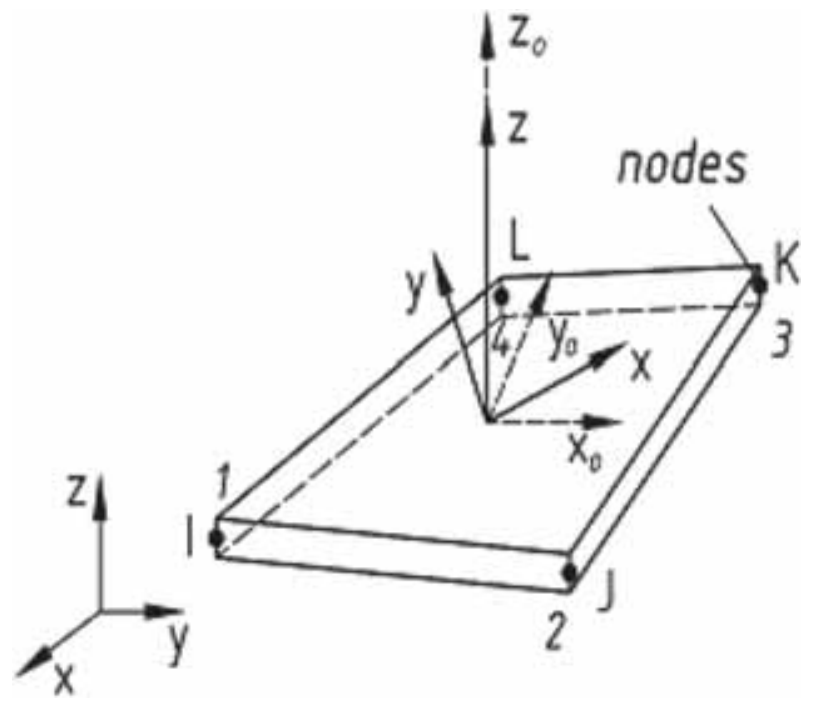

Figure 13. Geometry of Shell 181.

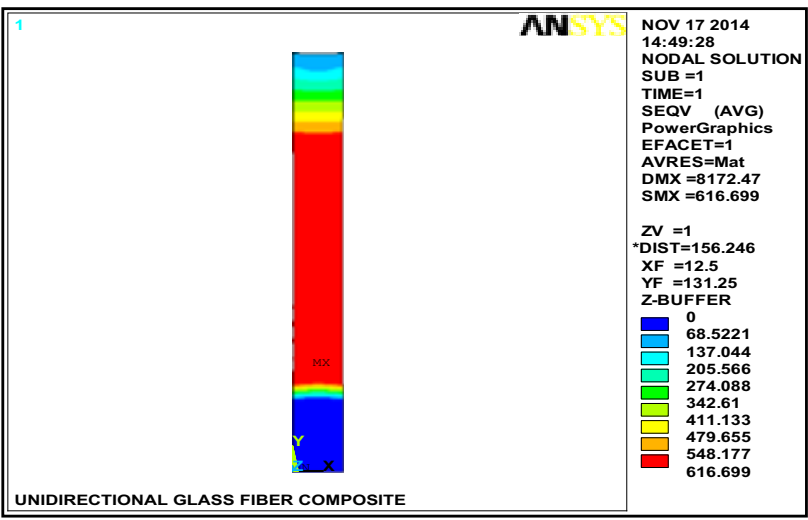

Figure 14. Sample equivalent of Von Misses stress for UGF composite.

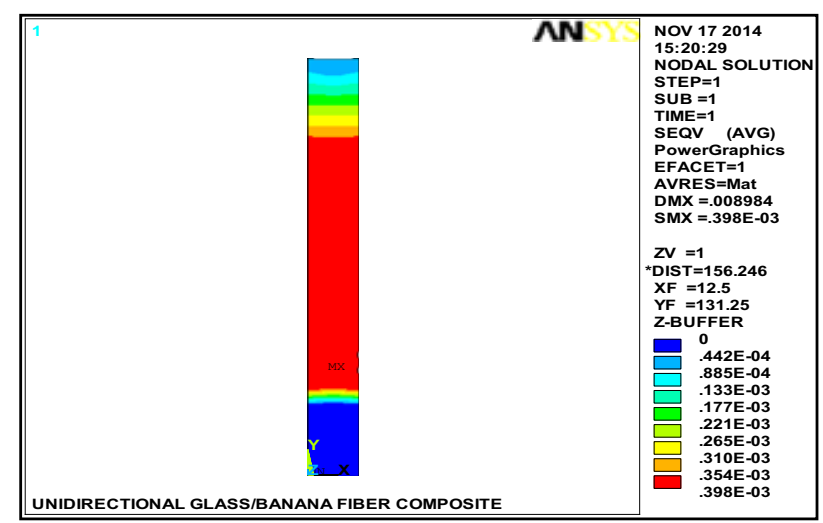

Figure 15. Sample equivalent of Von Misses stress for U B/G F composite.

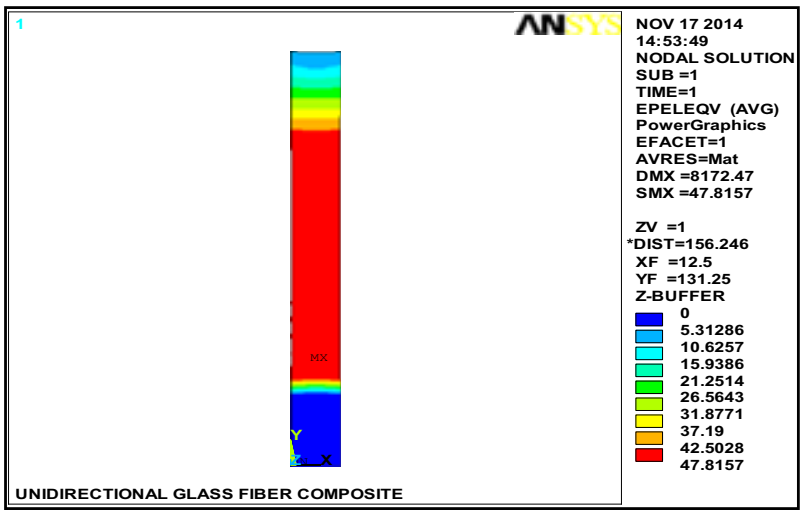

Figure 16. Sample equivalent of Von Misses strain for UGF composite.

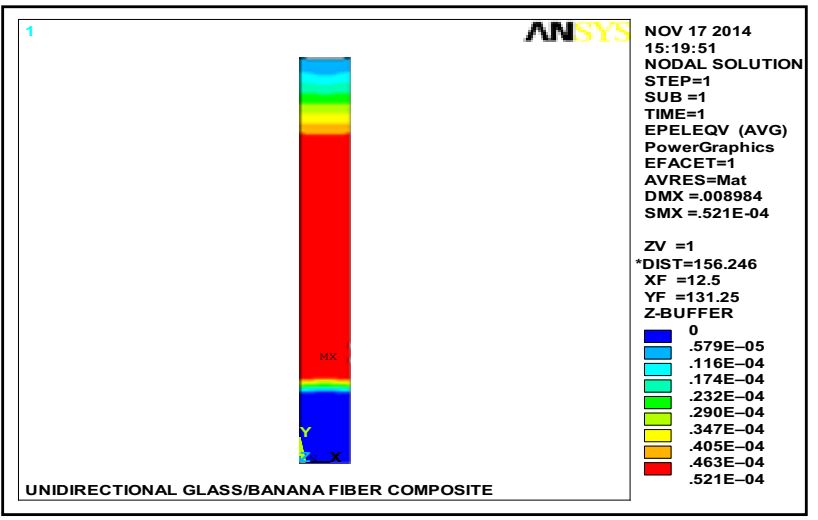

Figure 17. Sample equivalent of Von Misses strain for $U$ B/G F composite.

UGF - Experimental Vs Ansys stress

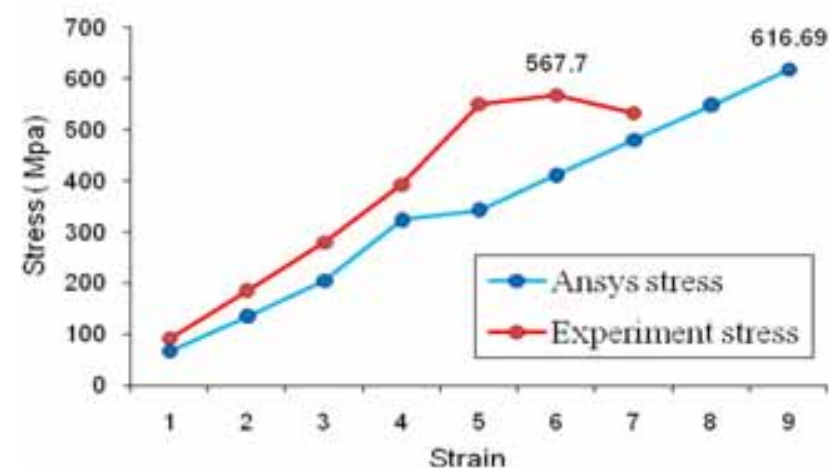

Figure 18. Comparative graph for UGF composite with experimental and Ansys stress.

$57.88 \mathrm{kN}$ for $\mathrm{UGF}$ and $38.88 \mathrm{kN}$ for $\mathrm{U} \mathrm{B} / \mathrm{G} \mathrm{F}$ composite. The average ultimate strength for UGF composite is noted as $498.9 \mathrm{Mpa}$ and for $\mathrm{U} \mathrm{B} / \mathrm{G}$ F composite is $296.7 \mathrm{Mpa}$. 


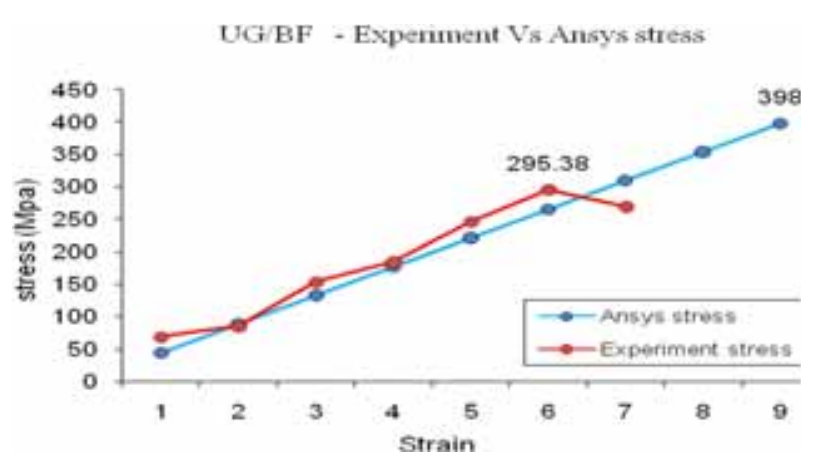

Figure 19. Comparative graph for $\mathrm{U} B / \mathrm{G} F$ composite with experimental and Ansys stress.

From this set of tensile values obtained, when the natural banana fiber is hybridized with glass fiber a moderate strength is observed and can be used in applications which require similar degree of strength especially house hold articles such as partition boards. The stress-strain curve and load-displacement curve is plotted and generated by the machine during testing and it is represented in figures 4-7. The maximum stress obtained is $567.7 \mathrm{Mpa}$ and 295.38 Mpa for UGF and U B/G F composites respectively. The average load-displacement is found to be $10.8 \mathrm{~mm}$ for the UGF composite and $11 \mathrm{~mm}$ for $\mathrm{U} \mathrm{B} / \mathrm{G} \mathrm{F}$ composite. From the load-displacement curves it can be noted that there is not much deviation and similar values for displacement are observed for both the UGF and $U$ B/G F composite samples with moderate load variation. From the curves generated, comparative chart and graph are drawn and they are presented in figures 8-11. The results indicated that the highest ultimate tensile strength is observed to be higher for UGF composite sample as $565 \mathrm{Mpa}$ at a load of $60 \mathrm{kN}$ and $296 \mathrm{Mpa}$ for U B/G F sample at a load of $38.8 \mathrm{kN}$. The result shows a drastic linear increase in extension with the increasing force. This is investigated with ANSYS for tensile test and its nodal solution is shown in figures 14-17. Experimental values for the tensile test are compared along with the numerical analysis using ANSYS and its comparative results of all the composite samples are shown in the graph represented by figures 18 and 19. Experimental stress value is $567.7 \mathrm{Mpa}$ and ANSYS Von Mises stress value is predicted to be 616.69 Mpa for UGF composite. Whereas for the U B/G F composite the observed values are 295.38 Mpa for experimental stress and $398 \mathrm{Mpa}$ for predicted Von Mises stress. From the analysis of the results it is revealed that the tensile test for numerical analysis is better than experimental results. This difference may be due to the assumptions in numerical analysis such as increase in interfacial bonding and strong interaction between the fiber and matrix with good bonding without slippage. Here the fibers are perfectly aligned and arranged in regular and symmetrical manner by unidirectional arrangement, provided the fibers are not porous and have uniform diametrical properties

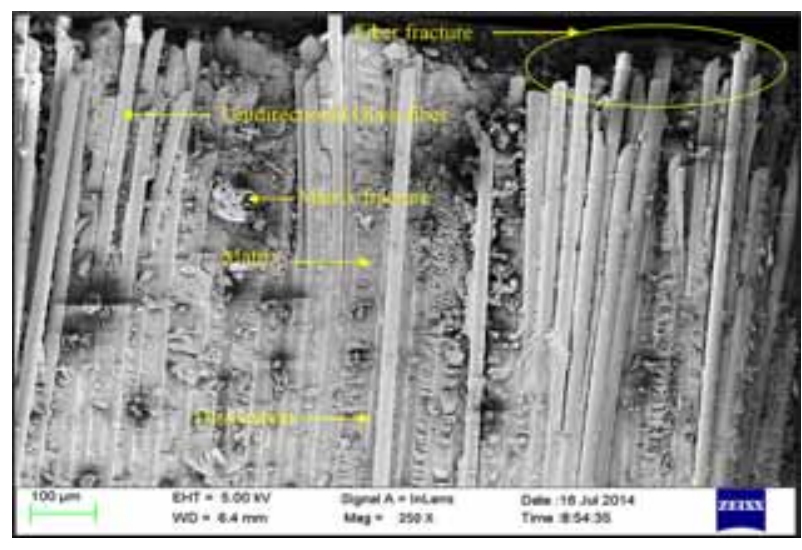

Figure 20. SEM image of UGF composite underwent tensile test of magnification factor $250 \times$.

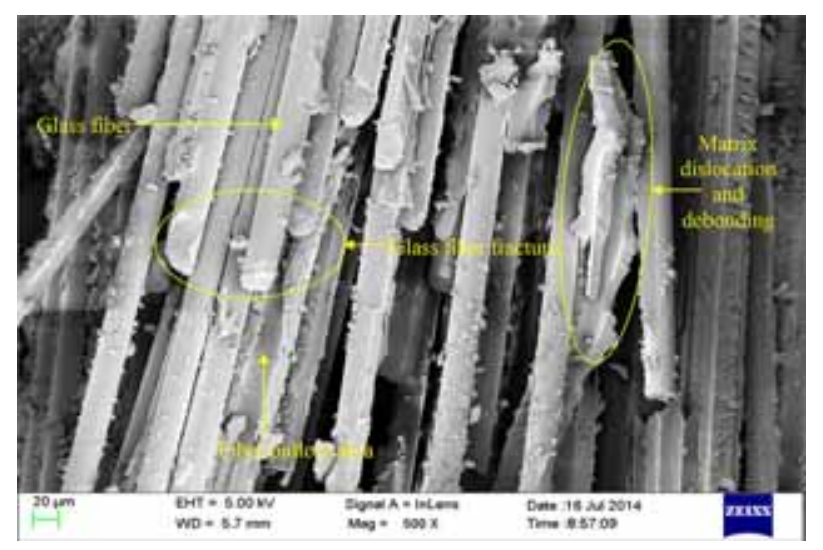

Figure 21. SEM image of UGF composite underwent tensile test of magnification factor $500 \times$.

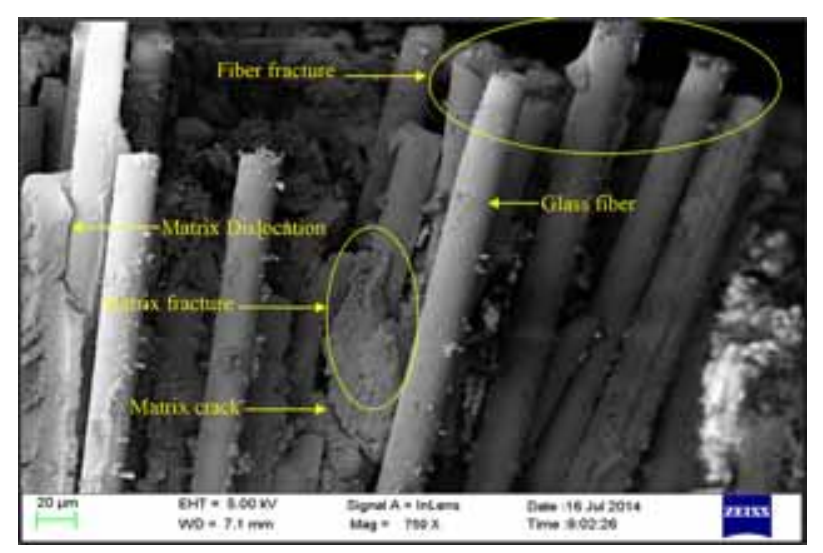

Figure 22. SEM image of UGF composite underwent tensile test of magnification factor $750 \times$.

throughout the composite. But in experimental analysis we come across fabrication defects in composites like presentation of voids, non-uniformity in matrix distribution, nonalignment of fibers along its axis as well as poor 


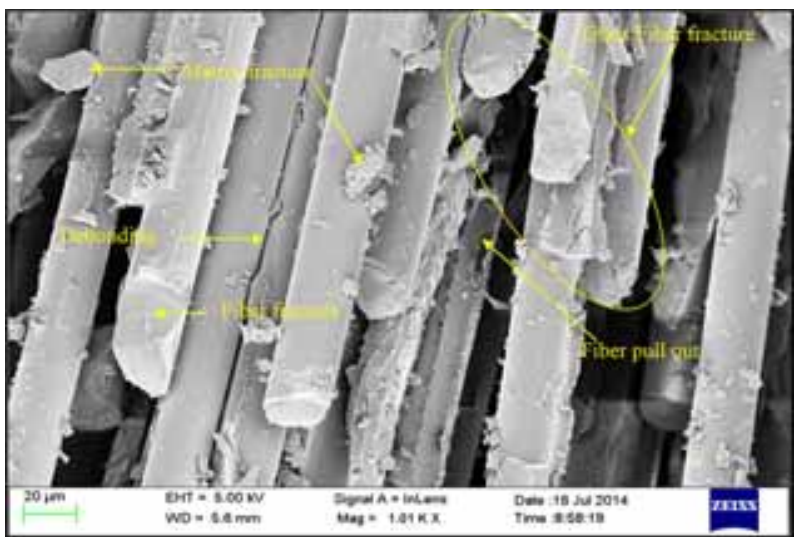

Figure 23. SEM image of UGF composite underwent tensile test of magnification factor $1000 \times$.

bonding with the resin, etc. These are the major parameters observed in both numerical and experimental analyses for the difference of correlation with the results.

\subsection{Scanning electron microscope (SEM) analysis}

The scanning electron microscope is used to examine microscopic detail of solid specimen that may have initially been viewed in a light microscope but subsequently found to require SEM examination in order to provide information not available from the light microscope. The image is produced by scanning an extremely small focused beam of electrons, adjustable down to a few nanometers in diameter, across the surface of a specimen in an array of picture points usually 1024 by 768 pixels. High energy electron bombardment of the specimen causes signals to be emitted at each pixel. These are collected and their intensities are used to produce images of the specimen by modulating the brightness of equivalent pixels on a TV monitor. Initial viewing of the specimen uses the secondary electron emission signal to provide an image very similar in shape to that seen in the light microscope. Unlike the light optical microscope that displays images in true color the SEM presents intensity images where zero signal is displayed as black, intermediate signals as shades of grey and maximum signal as white. The SEM images were collected from Carl Zeiss SUPRA 55 FESEM having resolution of $0.8 \mathrm{~nm}$ and the magnification factor ranges from $100 \mathrm{X}$ to $1000 \mathrm{kX}$. The SEM images of UGF and $\mathrm{U} B / \mathrm{G} F$ composite samples underwent tensile test is presented in figures 20-29 of magnification factor of resolution $250 \times, 500 \times, 750 \times$, $1000 \times$ and $1500 \times$. The fracture takes place in the composites by the application of tensile load. The SEM images indicate the bonding nature between the fiber and matrix and it is known that based on the interfacial bonding strength between matrix and fiber, the tensile property of composites will get varied. Layer of natural banana fiber and glass fiber is noted as alternate sequence in the

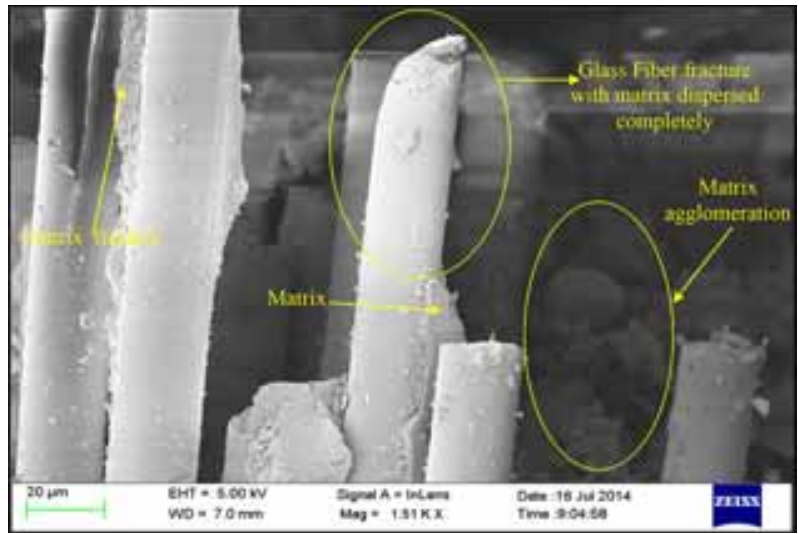

Figure 24. SEM image of UGF composite underwent tensile test of magnification factor $1500 \times$.

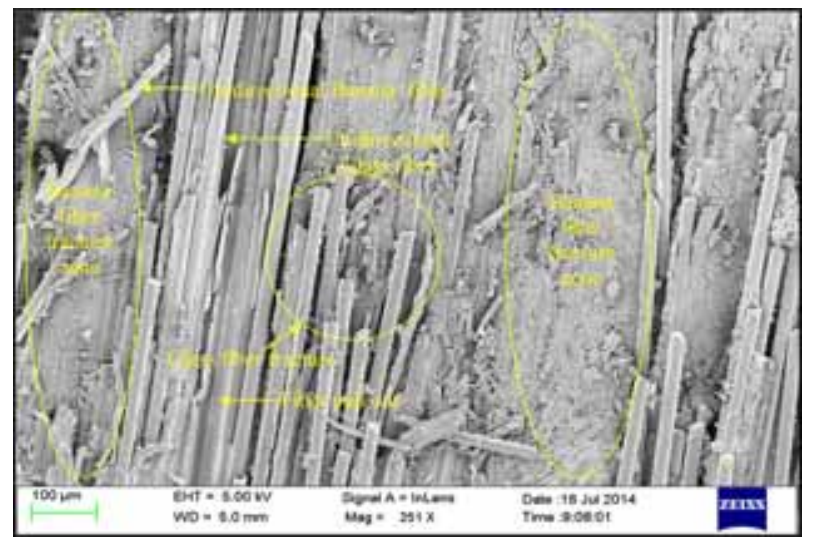

Figure 25. SEM image of U B/G F composite underwent tensile test of magnification factor $250 \times$.

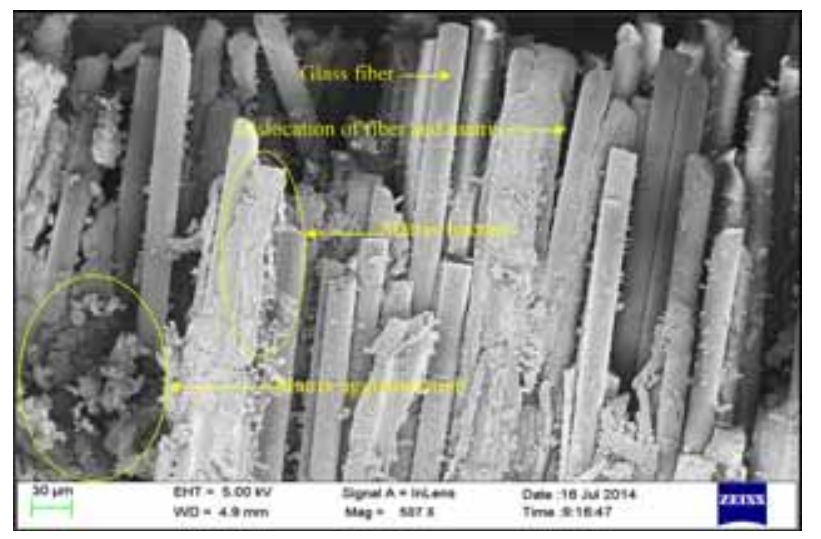

Figure 26. SEM image of $U$ B/G F composite underwent tensile test of magnification factor $500 \times$.

micrograph of figure 25 . The fiber fracture at the tension side is identified without resin sticking to the fiber which shows a poor fiber matrix adhesion result in reduction of tensile strength observed in figure 24. Fiber fracture, fiber 


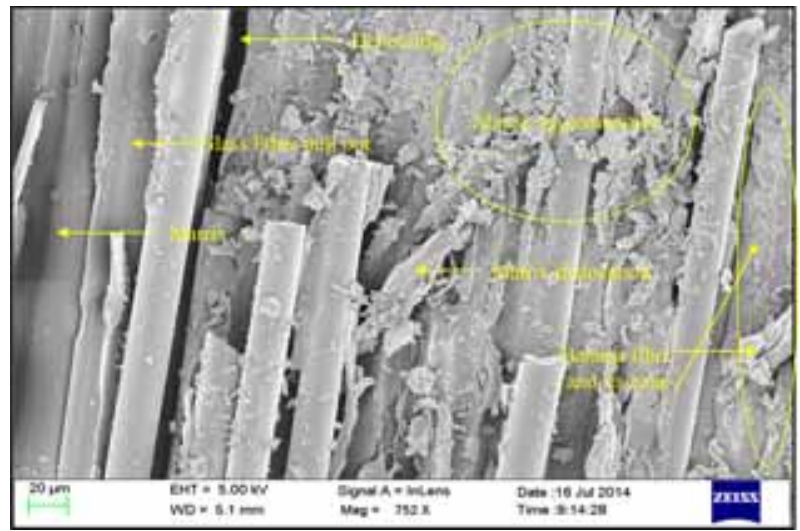

Figure 27. SEM image of $U$ B/G F composite underwent tensile test of magnification factor $750 \times$.

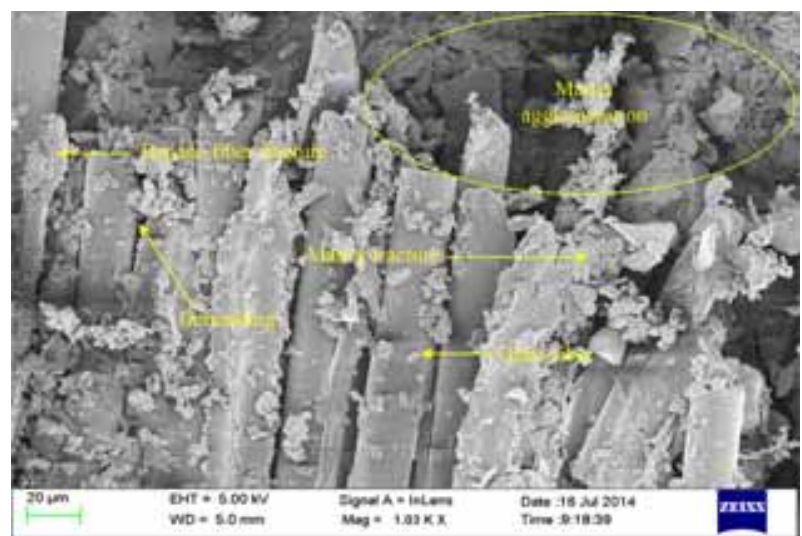

Figure 28. SEM image of $U$ B/G F composite underwent tensile test of magnification factor $1000 \times$.

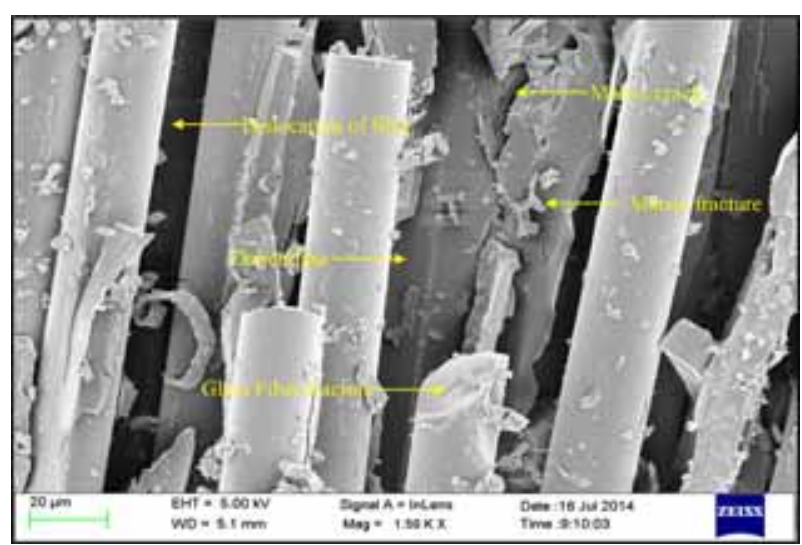

Figure 29. SEM image of $U \mathrm{~B} / \mathrm{G}$ F composite underwent tensile test of magnification factor $1500 \times$.

pullout, matrix fracture and debonding as well as dislocation of fibers are analyzed on the cross section of the tested specimens. These are the factors which are observed in the SEM analysis and are the main cause for the reduction of tensile strength.

\section{Conclusions}

In this paper a unidirectional glass fiber epoxy laminate and unidirectional banana/glass fiber epoxy laminate samples are fabricated. These composites are subjected to tensile testing using the universal testing machine. Based on the experimental and the numerical investigation followed by SEM micrographs the following conclusions are drawn.

- The UGF composite possesses higher ultimate tensile strength among the samples and can withstand the strength up to $567 \mathrm{Mpa}$ at a load of $60 \mathrm{kN}$.

- Experimental stress value is $567.7 \mathrm{Mpa}$ and ANSYS Von misses stress value is predicted to be $616.69 \mathrm{Mpa}$ for UGF composite. On the other hand a value of 295.38 Mpa as experimental stress and $398 \mathrm{Mpa}$ are obtained for predicted von misses stress for $\mathrm{U} B / G \mathrm{~F}$ composite.

- The average load-displacement is found to be $10.8 \mathrm{~mm}$ for the UGF composite and $11 \mathrm{~mm}$ for $\mathrm{U}$ $\mathrm{B} / \mathrm{G} \mathrm{F}$ composite, hence it can be used in applications which require moderate strength, especially in house hold articles such as partition boards.

- From the results, based on experimental and numerical analysis using ANSYS, the deviation is mainly due to the assumptions in numerical analysis such as increase of interfacial bonding, between fiber and matrix, alignment of fibers, non porous, uniform diameter of fibers and these assumptions make the predicted tensile value to be higher for UGF and U B/G F composite.

- In experimental analysis fabrication defects in composites such as voids, cracks, matrix and fiber fracture, poor bonding, improper matrix distribution and nonalignment of fibers are the probable causes for obtaining lower tensile value for UGF and U B/G F composite when compared with the numerical analysis.

- The surface morphology of the tested samples is analyzed using SEM in which fiber fracture, fiber pullout, matrix fracture and debonding as well as dislocation of fibers are observed.

- By chemically treating the natural fibers we may enhance the tensile strength of the composites.

- The usage of natural fibers replacing the synthetic fibers has been used in many applications which require medium strength.

- The natural fibers are non-hazardous and are also ecofriendly hence much research is required to make a composite having natural fiber in which tensile property is nearly equal to glass fiber.

\section{References}

[1] Ayensu A 2000 Interfacial debonding of natural fibre reinforced composites. Q. Sci. Vis. 6(1): 25-34 
[2] Palani Kumar K and Shadrach Jeya Sekaran A 2014 Some natural fibers used in polymer composites and their extraction processes: A review. J. Reinforced Plastics Compos. 33(20): 1879-1892

[3] Sharma N K and Kumar V 2012 Studies on properties of banana fiber reinforced green composite. J. Reinforced Plastics Compos. 32(8): 525-532

[4] Udaya Kiran C, Ramachandra Reddy G, Dabade B M and Rajesham S 2007 Tensile properties of sun hemp, banana and sisal fiber reinforced polyester composites. J. Reinforced Plastics Compos. 26(10): 1043-1050

[5] Indira K N, Parameswaranpillai J and Thomas S 2013 Mechanical properties and failure topography of banana fiber PF macrocomposites fabricated by RTM and CM techniques. ISRN Polymer Science volume., Article ID 936048, 8 pages, Hindawi Publishing Corporation

[6] Venkateshwaran N, Elayaperumal A and Sathiya G K 2012 Prediction of tensile properties of hybrid natural fiber composites. Compos. Part B 43: 793-796

[7] Rathika S, Palanikumar K and Raghavan P S 2014 Studies on physical performance of sisal-palf-banana/glass fiber reinforced polyester hybrid composites. Asian J. Chem. 26(6): 4157-4161

[8] Ramesh M, Palanikumar K and Hemachandra Reddy K 2013 Comparative evaluation on properties of hybrid glass fibersisal/jute reinforced epoxy composites. Proc. Eng. 51: 745-750

[9] Maleque M A, Belal F Y and Sapuan S M 2007 Mechanical properties study of pseudo-stem banana fiber reinforced epoxy composite. Arabian J. Sci. Eng. 32 (2B): 359-364

[10] Arumuga Prabu V, Manikandan V, Uthayakumar M and Kalirasu S 2012 Investigations on the mechanical properties of red mud filled sisal and banana fiber reinforced polyester composites. Mater. Phys. Mech. 15: 173-179

[11] Thiruchitrambalam M, Alavudeen A, Athijayamani A, Venkateshwaran N and Elaya Perumal A 2009 Improving mechanical properties of banana/kenaf polyester hybrid composites using sodium laulryl sulfate treatment. Mater. Phys. Mech. 8: 165-173

[12] Sathishkumar T P, Navaneethakrishnan P and Shankar S 2012 Tensile and flexural properties of snake grass natural fiber reinforced isophthallic polyester composites. Compos. Sci. Technol. 72: 1183-1190

[13] Singh S, Kumar P and Jain S K 2013 An experimental and numerical investigation of mechanical properties of glass fiber reinforced epoxy composites. Adv. Mat. Lett. 4(7): 567-572
[14] Subba Rao P, Anandatheertha S, Narayana Naik G and Gopalakrishnan S 2015 Estimation of mechanical properties of single wall carbon nanotubes using molecular mechanics approach, Sadhana 40(4): 1301-1311

[15] Gutu M 2012 Experimental and numerical analysis of stresses and strain in specimen of composite material. Merdian Ingineresc. 4: 24-27

[16] Lakshmi Narayana A, Krishnamohana Rao G and Vijaya Kumar R 2014 Buckling analysis of rectangular composite plates with rectangular cutout subjected to linearly varying in-plane loading using fem. Sadhana 39(3): 583-596

[17] Hossain Md. R, Islam Md. A, Van Vuurea A and Verpoest I 2013 Tensile behavior of environment friendly jute epoxy laminated composite. Proc. Eng. 56: 782-788

[18] Khalifa M and Chappar S S 2014 Experimental investigation of tensile properties of banana reinforced epoxy composites. Int. J. Sci. Res. 3(6): 832-836

[19] Ihueze C C, Okafor C E and Okoye C I 2015 Natural fiber composite design and characterization for limit stress prediction in multiaxial stress state. J. King Saud Univ. Eng. Sci. 27: 193-206

[20] da Silva L J, Panzera T H, Christoforo A L, Durão L M P and Lahr F A R 2012 Numerical and experimental analyses of biocomposites reinforced with natural fibres. Int. J. Mater. Eng. 2(4): 43-49

[21] Dyson Bruno A and Baskaran M 2014 Analysing the mechanical properties of natural fiber reinforced polymer composites using FEA. Int. J. Eng. Sci. Res. Technol., Bruno 3(1): 269-282

[22] Velmurugan G, Vadivel D, Arravind R, Vengatesan S P and Mathiazhagan A 2012 Tensile test analysis of natural fiber reinforced composite. Int. J. Mech. Ind. Eng. ISSN No. 2231-6477, 2(4): 56-60

[23] Ramakrishnan S, Krishnamurthy K, Mohan Prasath M, Sarath Kumar R, Dharmaraj M, Gowthaman K, Sathish Kumar P and Rajasekar R 2015 Theoretical prediction on the mechanical behavior of natural fiber reinforced vinyl ester composites. Appl. Sci. Adv. Mater. Int. 1(3): 85-92

[24] Venkateshwaran N and Elayaperumal A 2010 Banana fiber reinforced polymer composites-A review. J. Reinforced Plastics Compos. 29(15): 2387-2396

[25] Desai C S and Abel J F 1972 Introduction to the finite element method. Van Nostrand Reinhold Company, New York 